\title{
Impact of Lessepsian Migration of Marine Species through Suez Canal Locations on Genetic Diversity of Seabass Species Using Diffe rent Molecular Techniques
}

Rabie, Tarik; Deina M. Ahmed*and Zizi Elbialy** Department of Animal Production and Fish Resources Faculty of Agriculture Suez Canal University.tarik.rabie@agr.suez.edu.eg *Biotechnology department, Fish farming and technology institute,

Suez Canal University deinaahmed@ymail.com **Association professor of Genetics and Genetic Engineering Department of Fish Processing and Biotechnology Faculty of Aquatic and Fisheries Science Kafr-Elsheikh University,

\section{zizielbialy74@gmail.com}

\section{Abstract}

The main goal of this study was to estimate genetic differences of samples of European Sea bass from three different locations (Red Sea, Mediterranean and Suez Canal). A total of sixty-four samples have been collected during the period from October to January... with average weight ranged from 250-300 gm. Morphometric traits such as fish weight, body length, tail length and others were measured. From the samples of each location, The DNA extracted individually using QIAGEIEN kit. Two biotechnology techniques have used [Restriction Fragment Length Polymorphism based on polymerase chain reaction (PCR-RFLP) and Sodium Dodecyl Sulfate-Polyacrylamide Gel Electrophoresis (SDS-PAGE) ] to distinguish the genetic variants among the locations under the investigation. The morphometric traits show no significant differences between the samples from the three locations. The similarity matrix showed strong similarities between samples of Mediterranean Sea and the Suez Canal. Furthermore, samples from Red sea were more distinct from those of Mediterranean Sea and Suez Canal, although ecosystem of Red Sea and Mediterranean Sea are closely related, the similarity between them reached 55\%; otherwise, it is $75 \%$ between samples of both Suez Canal and Mediterranean Sea. Furthermore, SDS-PAGE analysis in the samples of Suez Canal were genetically in close related to both of Mediterranean and Red Seas. In addition, heat map's results emphasize the obtained results. From the present study, both PCR-RFLP and the SDS-PAGE had proved to be exceedingly successful in distinguishing between samples under study and genetic assorted variety between them. 
Key words : European Sea bass, Similarity, QIAGEIEN kit, PCRRFLP, SDS-PAGE.

\section{Introduction}

Nowadays, The European

Seabass (Dicentrarchus labrax) has considered as one of the most popular and hugely consumed fishes as a source of animal protein, It is an important commercial species along the Mediterranean and Atlantic shores for both fishing and aquaculture techniques (Deniz and Cemal, 2003). It was the first non-salmonid marine species that cultured in Europe and nowadays it is consider as the most important commercial species which is widely cultured and raring in Mediterranean areas such as Greece, Italy, Spain, Turkey, Croatia and Egypt (FAO, 2006). The European Seabass is a predatory species of fishes found throughout the Mediterranean Sea and the Eastern Atlantic (Fritsch et al., 2007), carnivorous fishes, its feeding based on a little fishes and invertebrates. European bass are a very slow-growing species that takes several years to reach full adulthood, its life span may reach to about 30 years, although it tends to be shorter in the Mediterranean Sea (Souto and Villanueva, 2003). Its maximum size reaches to over $1 \mathrm{~m}$, and weight of over $12 \mathrm{~kg}$ (Moretti et al., 1999).

Population genetics of European sea bass differentiation is one of the best studied among European marine fishes. In this study, two techniques: Sodium Dodecyl Sulfate-Polyacrylamide Gel Electrophoresis (SDS-PAGE) and Restriction Fragment Length Polymorphism (RFLP), were used to identify the variants between the Sea bass among the different geographic locations (Red sea, Suez Canal, and Mediterranean), together with detecting the specific molecular variant of the gene (s) causing the genetic variation.

\section{Mate rials and Methods Collecting data and samples}

Fishes were selected randomly with similar size, and the nearest weights (ranging from 200 to $300 \mathrm{gm}$ ), discarding sex factor. Sixty-four Fishes of European Sea bass, (Dicentrachus Labrex, ) have been collected from three different locations: Mediterranean Sea, Red Sea and Suez Canal as shown in Figure (1). All samples were collected from each location separately and putted immediately in a closed iced tank until reach to the biotechnology laboratory of the Fish Farming and Technology 
Institute, Suez Canal University, at the same day. The morphometric traits (Weight, Length, Width, Tail length, Body and Operculum lengths) were recorded. About $10 \mathrm{gm}$ from fresh flesh were taken and freeze at $-20^{\circ} \mathrm{C}$ until DNA extraction.

\section{DNA extraction}

Genomic DNA extracted by using PureLink Genomic DNA Mini; Microcentrifuge spincolumn format (Invitrogen ${ }^{\mathrm{TM}}$ $\mathrm{K} 182001$, USA) to provide a flexible method that meets the requirements of current demands including: Superior performance and high purity and yield of extracted DNA. The quality of extracted DNA examined by NanoDrop ${ }^{\circledR}$ ND-1000 UV-V is Spectrophotometer enabling highly accurate analyses of extremely small samples with remarkable reproducibility.

\section{PCR Reaction}

The COI marker (Forward sequence $5^{\prime}-$

TCTCAACTAACCAYAAAG AYATYGG-3', sequence $5^{\prime}$ -

AGACTTCTGGGTGGCCRAA

RAAY-3) was used for PCR amplification; each $25 \mu$ reaction contained 40ng template gDNA, $12 \mu \mathrm{l}$ 2X MasterMix (Qiagen), 20 pmole for each primer and miliQ water. Master thermocycler gradient
(Eppendorf) was used for amplification using the subsequent thermal profile as a pair of minutes at $94^{\circ} \mathrm{C}$ as initial denature step, followed by thirty-five amplification cycles (30s at $94^{\circ} \mathrm{C}, 30$ s at $52^{\circ} \mathrm{C}, 3 \mathrm{~min}$ at $72^{\circ} \mathrm{C}$ ), then one final elongation step for $10 \mathrm{~min}$ at $72^{\circ} \mathrm{C}$.

\section{Detection of flesh protein} fractions by SDS-PAGE:

The pooled samples from each location was performed. The protein bands and its variations were identified using Sodium Dodecyl sulfate Polyacrylamide Gel Electrophoresis (SDSPAGE) as described by Laem mi (1970); and its modified protocol, where five progressively steps where 1040mg flesh sample was homogenized with $1500 \mu \mathrm{l}$ extraction buffer, following the modifications that described by Rabie (2010). Ten $\mu$ of each sample was loaded in a different lane in the pre-prepared SDSPAGE gel. Ten $\mu$ of the Spectra $^{\mathrm{TM}}$ standard multicolor broad range protein ladder (Fermentas ${ }^{\circledR}$ ) ranging between 260-10 kDa was also loaded in a separate lane. Subsequently, the gel electrophoresis was carried out at 90 Volt and $50 \mathrm{mAmps}$ for 8 hours. The separation gel was then lifted off the electrophoresis glass sheets and stained with "Coomassie Stain" 
for 12 hours then distained for more 12 hours. The separated gel was pictured and analyzed a "Gel Documentation System" (GDS) . Analysis of the separated protein bands

The SDS-PAGE images were analyzed as described by Rabie (2012), first examined by using the GDS followed by AAB software, then the taxa were used for further analysis, therefore the simple band match similarity has calculated. Migrating mobility $(R f)$ SDS-PAGE was calculated according to the following equation:

$$
R F=\frac{\text { The migration distance of the band }}{\text { The migration distance of the indication dye }}
$$$$
\text { PCR-PFLP }
$$

Two restriction enzymes were used (HspAI and HapII) to characterize the differences between the studied locations based on the PCR product of the COI gene that used as a DNA barcoding (PCR-RFLP).

\section{Data Analysis \\ manipulation \\ RFLP analys is}

For statistical analysis PCRRFLP data, each individual band was considered as a single locus/allele. Alleles/loci (bands) were scored as present (1) or absent (0). Genetic diversity was estimated using following formula (Nei and $\mathrm{Li}$, 1979) andaccording Rabie (2010) recommendation wherever GD = 1 - dxy/dx + dy-dxy where; GD $=$ Genetic distance between two genotypes, $d x y=$ number of common bands 2 genotypes by using Past Software (Hammer $\boldsymbol{e} t$ al., 2001).

Analysis of the separated protein bands.

This study, the SDS-PAGE images were analyzed as described by Rabie (2012), the taxa were used for further analysis. Therefore, the simple band match similarity has calculated where, the algorithm iteratively combines the two nearest clusters, until one cluster is left. Simple band match has been calculated using $\mathrm{AAB}$ software depending number bands shared between the samples. This method is fast but requires that bands be marked. Percent error may be set; this is defined as a percent bands distance that another band must be order for the two be called the same band. 3.2\% has been used as a percent error where. Higher Percent Match $=$ Higher Similarity. Percent match ranges from $100 \%$ to $0 \%$.

\section{Interpretation \\ Protein}

\section{Patterns data}

SDS-PAGE Protein profiles were used for estimation the genetic similarity as well as genetic distance between the Sea bass that collected from three different locations based on band frequency. The results were analyzed by comparing the patterns on the basis of the presence (1) or absence (0) of each band on the gel. A data 
matrix was constructed. GelQuest software Version 3.0.5 (SequentiX - Digital DNA Processing, Klein Raden, Germany) was used to analyze DNA fingerprint profiles and fragment patterns followed by using Past software to construct phylogenetic tree. For the calculation of similarities or dissimilarities (distances), the number of total matches (a), single matches $(b, c)$ and no matches (d) are calculated out of the number of total positions $(n=a+b+c+d)$. Therefore, the matrices were analyzed to evaluate the differences resulting from the use of Jaccard (Jaccard, 1901) followed by Simple Matching similarity coefficient accompanied with NJ-neighbor-Joining cluster algorithm as recommended by Rabie (2010). Levels of statistical significance are not given because the analyses are derived from a single initial data matrix and therefore lack independence.

Statis tical analysis

Shapiro-Wilk normality test as proposed a highly intuitive goodness-fit test normality nuisance location and scale parameters were performed (Shapiro and wilk, 1965) followed by a Quantile Quantile Plot (Q- Q plot). This can give a judgement "goodness of fit" that is graphical, instead diminishing a numerical synopsis. Both goodness fit and analysis of variance were implemented by the R packages ( $R$ Core Team, 2013). The analysis was performed according to the following equation:

$\mathrm{Y}_{\mathrm{ij}}=\mu+\mathrm{L}_{\mathrm{i}}+\varepsilon_{\mathrm{ij}}$

where $\mu$ is the overall mean, $\mathrm{Li}$ is the effect of ith location $(12,3)$ and $\varepsilon \mathrm{ij}$ is the random error. Means, and standard errors for all measurable traits were estimated by using "multicomp" package R according Hothorn et al. (2008), and a compact letter display (Duncan) method that listings the means accompanied by symbols for contrasts, and $\mathrm{P}$ value adjustment method which are available from the comprehensive $\mathrm{R}$ archive network (https://cran.rproject.org/) . 


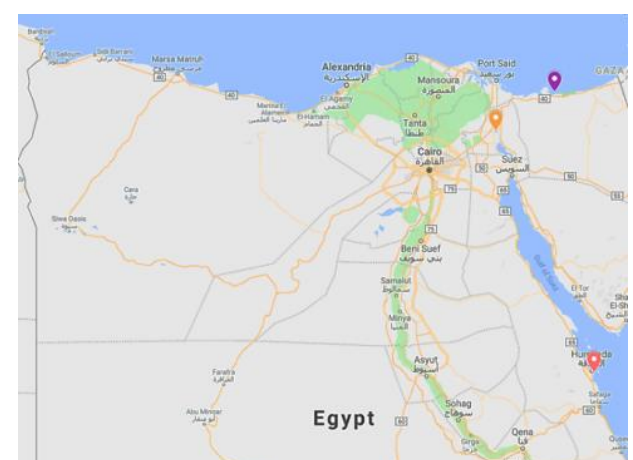

Figure (1): Illustration of collected samples locations, where the GPS locations were marked at the map as Red: Red Sea (Hurgada), Purple: Mediterranean Sea (Bardawil Lake) and Orange: Suez Canal.

Results and Discussion

\section{Goodness of fit analys is}

For small samples size the Shapiro-Wilk test performs much better than any other normality test. The $\mathrm{P}$-value is larger than $\alpha 0.05$, Therefore, the hypothesis that the respective distribution is normal should not be rejected (Rabie, 2019). If the sample size is adequately expansive this test may distinguish even unimportant takeoffs from the null hypothesis, as occasion, despite the fact that there might be some impact of statistically significance, it might be too small even think about being any practical significance. As a sample size was varied from 20 24 per location, thus, additional investigation of the effect size is typically advisable (Field, 2009) and performed as $\mathrm{Q}-\mathrm{Q}$ plot. The results revealed that the data of the given samples are valid for further statistical analysis.
Where, Q- Q plot is commonly a more dominant way to deal with this than the basic procedure and is generally used to contrast an informational collection with a hypothetical model (Thod, 2002). Q- Q plots are additionally used to compare two theoretical distributions with each other (Gibbons and Chakraborti, 2003). Therefore, the analysis of variance was implemented for body weight, Fish Length, Operculum Length, Body Length, Tail Length, and Fish Width, which revealed that there was a significant difference; $\quad \mathrm{W}=0.8757$, $(\mathrm{P} \geq 0.001)$ between the samples from the three locations (Fig. 2). Phenotypic analys is

The recorded data were statistically analyzed by using $\mathrm{R}$ ( $R$ Core Team, 2013), as presented in Table (1). All morphometric traits) had a coefficient variant $(\mathrm{CV})$ within the range $(8 \%-13 \%)$, while the 
body weight was more variable (31\%). Moreover, the morphometric traits were highly positively correlated among themselves and with Body weight. Massault et al., (2008) studied the biology of European Sea bass (Dicentrachus Labrex); they measured the morphometric traits of 922 organisms of European Sea bass. Their results show that the body weight and other eight-morphometric traits have $\mathrm{CV}$ within the same range (12-13\%), while Body weight has a CV $(35 \%)$.

Molecular identification by Protein electrophoresis analysis

Analysis of protein content considers as a master key of differentiation and similarities between different species as Proteins are the chief source of energy in fishes, since they live an environment that is very poor of carbohydrate (Lovell, 1989). However, little of genetic variance information of genetic variability of the Sea bass populations in Egypt exists. In this study, protein SDSPolyacrylamide Gel Electrophoresis was performed. A total of six samples of European Seabass (Dicentrachs Labrex, (by using flesh protein) from different locations (two replications for each location were used) (Figure 3). The protein fractions are identified in terms of their molecular weights, the values of protein fractions (\%) and molecular weight of each fraction are listed in Table (2). In addition, SDS-PAGE allows obtaining up to 36 proteins bands, the average of 12 bands for each lane the gel. The results revealed that, the bands obtained from Red Sea samples had unique molecular weight (MW) (149.01, 97.61, 71.71, $66.47, \quad 60.73, \quad 84.84, \quad 39.03$, $34.06, \quad 30.68$ and $23.18 \mathrm{kD}$ ) compared to the other two locations. Moreover, the bands obtained from Mediterranean Sea MW of 101.01, 80.44, 73.03, $50.06, \quad 89.95, \quad 39.1,5, \quad .0 .05$, $25.23,20.82,15.98 \mathrm{kD}$ was not exist in the other two locations similarly. The bands obtained from Suez Canal Area are numbered as 2nd protein band of MW 128.05, 62.86, 41.23, 38.89, $35.12,1.60,25.57 \mathrm{kD}$ were not exist in the other two locations too. According to densitometry analysis and cluster analysis (Figure 4), the Red Sea samples were distinct from those of the Mediterranean Sea.

\section{Phyloge netic Analysis}

In this study, SDS-Page analysis illustrated that samples of Suez Canal were genetically closely related to both of Mediterranean Sea and Red Sea. The result retrieved from the SDS-protein analysis evaluate the prospected variability among the samples from the three locations and examine genetic effects based 
the obtained bands. A phylogenetic tree based on Neighbor-Joining method; results phylogenetic diversity. Where, the similarity matrix showed that Strong similarities were found between samples of Mediterranean Sea and of the Suez Canal. Furthermore, samples from Red sea more distinct from each of samples of Mediterranean Sea and of Suez Canal. Although ecosystem of Red Sea and Mediterranean Sea are closely related, the similarity between them reached 55\%; otherwise, it is $75 \%$ between samples of both Suez Canal and Mediterranean Sea. In addition, the results obtained from the heat map analysis (Fig. 5) emphasize the obtained results. Caccone et al. (1997) used a different technique ,RAPD, they noticed that the variation withinpopulation was high, but between-population genetic differentiation was quite low. These differences might be caused by salinity, where a comparison with a previous study in which hatchery samples were repeatedly subjected to acclimation to freshwater, it was possible to detect an ecological component to the pattern of differentiation in wild samples. Moreover, Caccone et al. (1997) Identified a subset of RAPD bands that differed significantly in frequency between marine and lagoon samples. Also, the same bands were changed in their frequencies in the experimental samples after acclimated to freshwater, with the acclimated samples from lagoons. They suggest that markers are associated with genomic regions involved in tolerance for varying salinity levels and that the acclimation experiments reflected the differential survival of genotypes naturally occurring in lagoons.

\section{Restriction Fragment Length Polymorphism (RFLP)}

To find a suitable gene region for species identification, it is important to examine the degree of polymorphism exhibited among target and background species from different geographic regions (Teletchea et al., 2005). So that, two restriction enzymes were used (Hsp AI and HapII) to characterize the differences between the studied locations based on the PCR product of the COI gene that used as a DNA barcoding (PCR-RFLP). The result indicates that samples from Mediterranean Sea and Red Sea are more genetically similar (distance $=0.0175$ ) than those from Mediterranean Sea and Suez Canal Area, and Red Sea samples with Suez Canal Area (0.583,0.5750 respectively). The coefficient of the genetic similarities among the European Sea Bass's samples based on gene sequence data indicate that 
samples from Mediterranean Sea and Red Sea give high priority for conservation purposes based on genetic diversity (Fig. 6).

Needless, to report that more advanced analysis should be done on both level laboratory and bioinformatics analysis to get more information and add discovered results specially SNPs to the Sea bass' genetic maps. Where, Maretto et al. (2007) sequenced a 430 bp fragment of the mitochondrial 16S rRNA gene to identify four economically important species belonging to the Gadiformes. They identified three SNPs (single nucleotide polymorphism) that allows unambiguous discrimination between studied species. Therefore, this study emphasized the conservation decisions for fish genetic resources (based on Sea bass study) should consider not only molecular marker-based genetic diversity but also other factors such as specific traits, productive performance, and future economic interest.

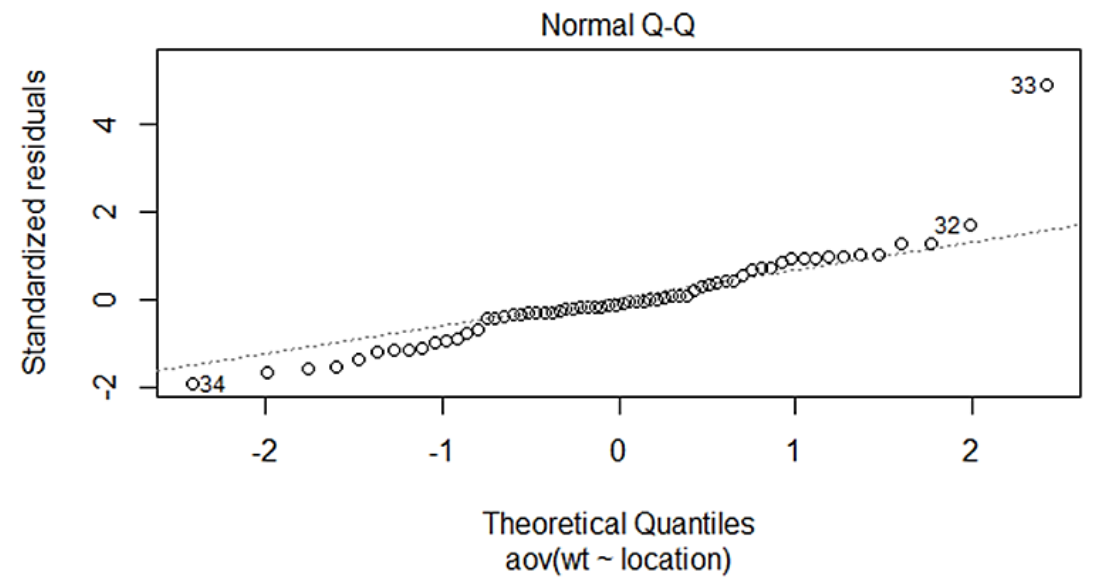

Figure (2): The normal Q-Q plot comparing randomly generated an independent standard normal data on the vertical axis to a standard normal population on the horizontal axis. The linearity of the points suggests that the data are normally distributed. 
Table (1): Effect of different locations on morphometric traits of European Sea bass.

\begin{tabular}{|l|l|l|l|}
\hline & Mediterranean Sea & Red Sea & Suez Canal \\
\hline Traits & \multicolumn{3}{|l|}{} \\
\hline Body weight $(\mathbf{g m})$ & $294.1 \pm 25.7$ & $255.8 \pm 9.7$ & $264.0 \pm 9.61$ \\
\hline Fish Length $(\mathbf{c m})$ & $25.6 \pm 0.55$ & $26.0 \pm 0.34$ & $26.2 \pm 0.38$ \\
\hline Operculum Length $(\mathbf{c m})$ & $7.4 \pm 0.16$ & $7.4 \pm 0.11$ & $7.4 \pm 0.11$ \\
\hline Body Length $(\mathbf{c m})$ & $18.2 \pm 0.51$ & $17.9 \pm 0.24$ & $17.9 \pm 0.24$ \\
\hline Tail Length $(\mathbf{c m})$ & $4.4 \pm 0.14$ & $4.5 \pm 0.11$ & $4.2 \pm 0.12$ \\
\hline Fish Width $(\mathbf{c m})$ & $6.1 \pm 0.18$ & $6.6 \pm 0.11$ & $6.5 \pm 0.12$ \\
\hline Condition Factor $(\mathbf{C F})$ & 1.7529 & 1.4553 & 1.4679 \\
\hline
\end{tabular}

$* \mathrm{CF}=$ Weight $/(\text { Length })^{3} \times 100$

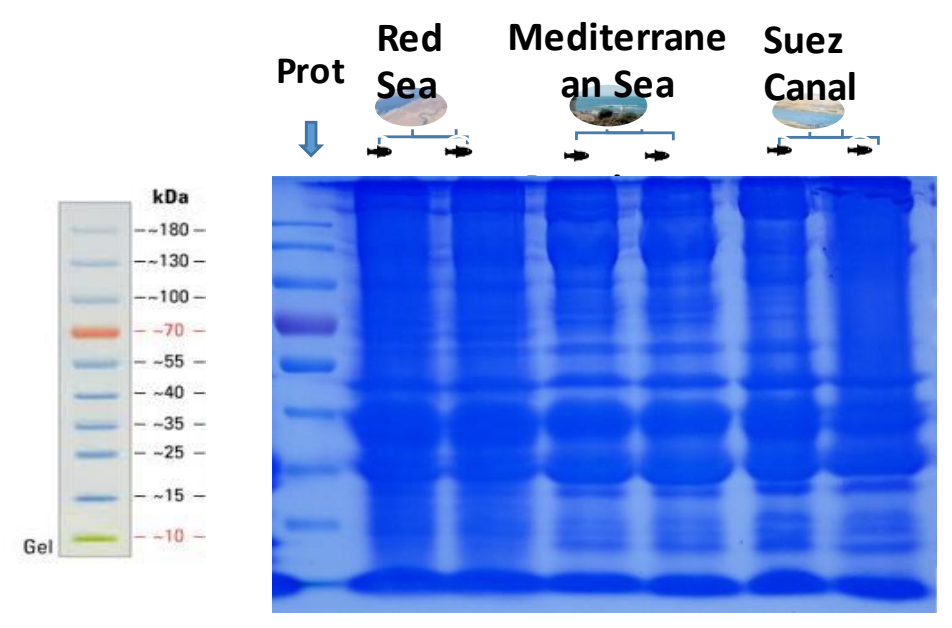

Figure (3): Protein pattern for flesh's Sea bass samples from Red Sea, Mediterranean Sea and Suez Canal using SDS-PAGE. 


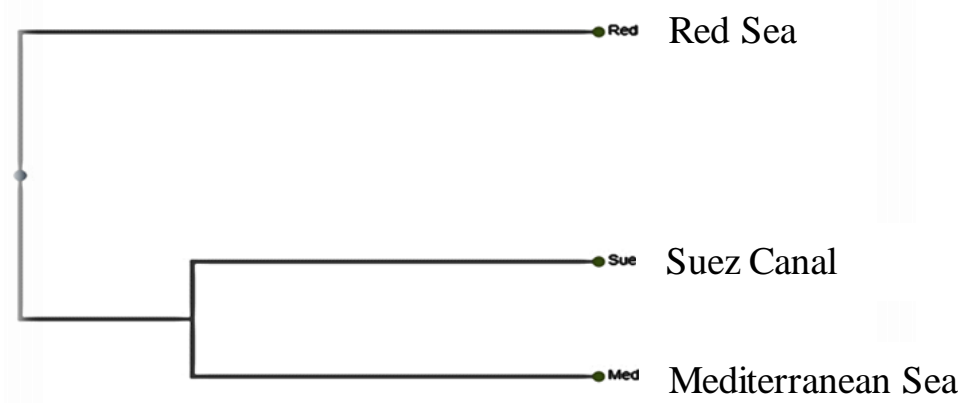

Figure (4): Phylogenetic tree for Red Sea, Mediterranean Sea and Suez Canal developed by NJ-cluster analysis combined with Jaccard coefficient algorithm among the European Sea bass samples based on Protein analysis.

Table (2): Protein retardation factor values in the identified flesh's samples of the Sea bass from the three sites using SDS-PAGE.

\begin{tabular}{|c|c|c|c|}
\hline Molecular Weight (kDa) & \multicolumn{3}{|c|}{ Retardation factor $(\boldsymbol{R} f)$} \\
\hline & Red Sea & Mediterranean Sea & Suez Canal \\
\hline 149.01 & 0.97 & -- & -- \\
\hline 128.05 & - & - & 0.97 \\
\hline 121.75 & 0.49 & 0.97 & -- \\
\hline 101.01 & -- & 0.48 & - \\
\hline 97.61 & 0.87 & - & - \\
\hline 80.44 & -- & 0.6 & - \\
\hline 73.03 & -- & 0.4 & -- \\
\hline 71.71 & 0.41 & -- & -- \\
\hline 66.47 & 0.71 & - & - \\
\hline 62.86 & -- & -- & 0.9 \\
\hline 62.05 & - & 0.74 & -- \\
\hline 60.73 & 0.62 & -- & - \\
\hline 49.96 & -- & 0.9 & -- \\
\hline 49.71 & - & -- & 0.75 \\
\hline 48.47 & 0.24 & -- & -- \\
\hline 41.23 & $\begin{array}{ll}- \\
-\end{array}$ & $\begin{array}{ll}- \\
-\end{array}$ & 0.87 \\
\hline
\end{tabular}




\begin{tabular}{|c|c|c|c|}
\hline \multirow[t]{2}{*}{ Molecular Weight (kDa) } & \multicolumn{3}{|c|}{ Retardation factor $(R f)$} \\
\hline & Red Sea & Mediterranean Sea & Suez Canal \\
\hline 39.1 & - & 0.86 & -- \\
\hline 39.03 & 0.14 & -- & -- \\
\hline 38.89 & -- & -- & 0.7 \\
\hline 35.12 & - & - & 0.48 \\
\hline 34.06 & 0.34 & -- & -- \\
\hline 33.6 & -- & 0.85 & -- \\
\hline 31.52 & $\begin{array}{ll}- \\
-\end{array}$ & -- & 0.59 \\
\hline 30.68 & 0.37 & -- & $\overline{--}$ \\
\hline 30.26 & -- & 0.14 & -- \\
\hline 25.57 & - & -- & 0.84 \\
\hline 25.23 & -- & 0.3 & -- \\
\hline 23.32 & -- & 0.77 & 0.55 \\
\hline 23.18 & 0.77 & -- & -- \\
\hline 20.82 & -- & 0.23 & -- \\
\hline 20.3 & -- & -- & 0.23 \\
\hline 16.08 & 0.11 & -- & 0.14 \\
\hline 15.98 & -- & 0.33 & -- \\
\hline
\end{tabular}

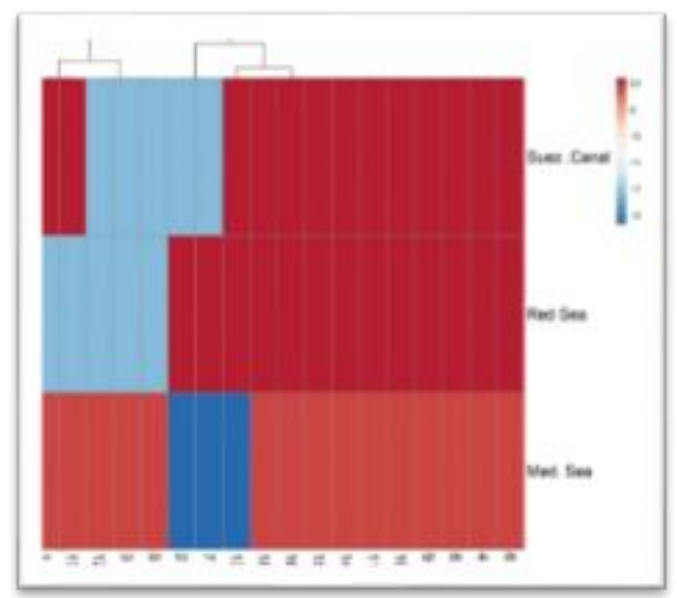

Figure (5): Heat map representation of the SDS-PAGE analysis for European Sea bass samples from three different locations (Suez Canal, Red Sea and Mediterranean Sea). 


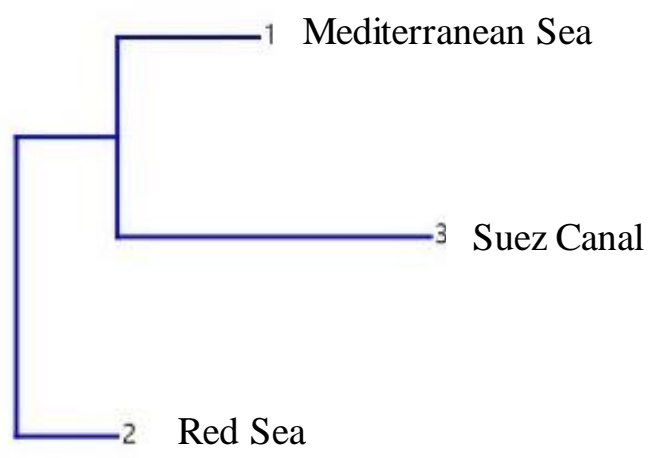

Figure (6): Phylogenetic tree developed by $\mathrm{NJ}$-cluster analysis among the European Sea bass samples based on PCR-RFLP among the European Sea bass's locations Red Sea, Mediterranean Sea and Suez Canal.

\section{References}

Deniz E., Cemal T., (2003). Examination of Genetic and Morphologic Structure of SeaBass (Dicentrarchus labrax L., 1758) Populations in Turkish Coastal Waters. Turk J Vet Animal Science 29: 727-733.

FAO (2006).: The State of the World Fisheries and Aquaculture, Food and Agriculture Organisation of the United Nations, Rome (2006).

Field A. (2009). Discovering statistics using SPSS (3rd ed.). Los Angeles [i.e. Thousand Oaks, Calif.]: SAGE Publications.

Fritsch M., Morizur Y., Lambert E., Bonhomme F., Guinand B. (2007). Assessment of sea bass (Dicentrarchus labrax, L.) stock delimitation in the Bay of Biscay and the English Channel based on mark- recapture and genetic data. Fisheries Research 83:123- 132. Gibbons J. D., Chakraborti, S. (2003). Nonparametric statistical inference (4th ed.), CRC Press, ISBN 978-0-8247-4052-8.

Hammer Ø., Harper D. A.T., Ryan P. D. (2001). PAST: Paleontological Statistics Software Package for Education and Data Analysis. Palaeontologia Electronica 4(1): 4-9p.

Jaccard P. (1901). Étude comparative de la distribution florale dans une portion des Alpes et des Jura. Bulletin de la Societe Vaudoise des Sciences Naturelles 37(142):547-579.

Laemmli, U.K.

(1970). Cleavage of structural proteins during the assembly of the head of bacteriophage T4. Nature, London 227: 680-685. 
Lovell T. (1989). Nutrition and Feeding Fish, Van Nostrand Reinhold Publishers, New York. Maretto F., Reffo E., Dalvit C. Gianni B., Roberto M. (2007). Finding 16S rRNA gene-based SNPs for the genetic traceability of commercial species belonging to Gadiformes. Italian Journal of Animal Science 6: 161-163.

Massault C., Bovenhuis H., Haley C., de Koning D. J. (2008). QTL mapping designs for aquaculture. Aquaculture 285: 23-29.

Moretti A., Fernandez-Cria do M. P., Cittolin G., Guidastri R. (1999). Manual Hatchery Production of Sea bass and Gilthead Seabream, Food and Agriculture Organization, the United Nations 1, Rome, Italy, $194 \mathrm{pp}$.

R Core Team (2013). R: A language and environment for statistical computing. R Foundation for Statistical Computing, Vienna, Austria. URL http://www.Rproject.org/

Rabie T. S. K. M (2019). Genetic Appraisals of Red Baladi and Sinai Gabali Rabbits Using Microsatellite Markers and DNA Barcoding. Egyptian Poultry Science 39: 235-251.

Rabie T. S. K. M. (2012). Interand intra- Breeds Divergence in
Rabbits using of SDSPAGE Protein Electrophoresis. 3 rd Medetranian poultry summit and 6th International conference for poultry sciences. Porto Marina, Egypt.

Rabie T. S. K. M. (2010). Implementation of Some Similarity Coefficients In Conjunction With Multiple Upgma and Neighbor-Joining Algorithms For Enhancing Phylogenetic Trees. Egyptian Poultry Science 30: 607-621. Shapiro S. S., Wilk M. B. (1965). An analysis of variance test for normality (complete samples). Biometrika 52: 591611.

Souto F. B., Villanueva X. L. R., (2003). European Fish Farming Guide. Galician Institute for Aquaculture Training (IGAFA), Pontevedra, Spain.

Teletchea F., Maudet C., Hanni C. (2005). Food and forensic molecular identification: update and challenges. Trends

Biotechnology 23: 359- 66.

Thode H. C. (2002). Testing for normality, Section 2.2.2, Quantile-Quantile Plots, p. 21) ISBN:0-8247-9613-6, Marcel Dekker,Inc, New York. Basel. 


\section{ثأثير الهجرة المستمرة من الأتواع البحرية المبر قناة السويس على التنوع

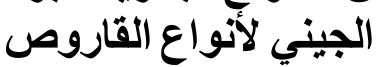

يعتبر القاروص الأوروبي (Dicentrachus labrex) واحدًا من أكثر أسماك الطعام

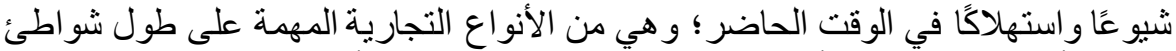

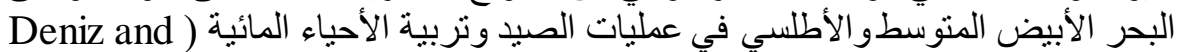

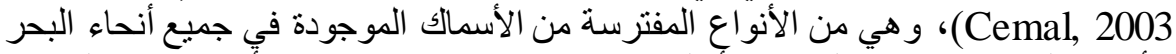

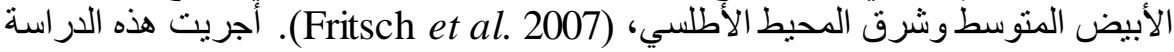

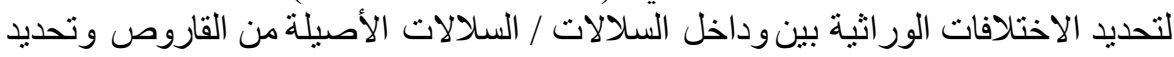

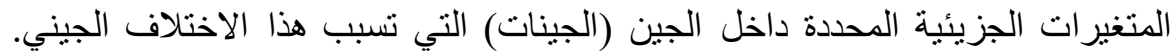

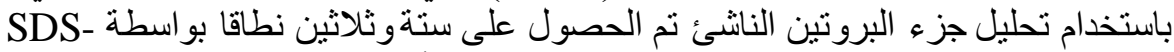

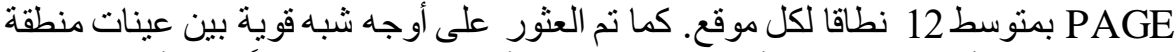

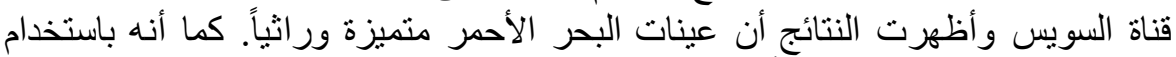

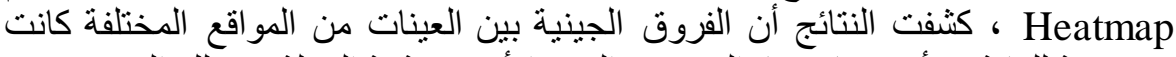

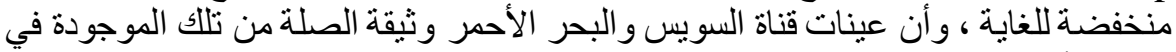

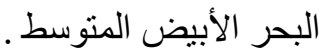

